\title{
El bupropión, sólo o en combinación con parche de nicotina, mejora la tasa de abandono del cigarrillo
}

A controlled trial of sustained released bupropion, a nicotine patch, or both for smoking cessation. Jorenby D.E:, Leischow S.J., Nides M.A: et al. NEJM; 1999; 340:685-91

\section{Objetivo}

Comparar la eficacia del bupropión, los parches de nicotina, ambos tratamientos combinados y placebo para dejar de fumar.

\section{Diseño}

Estudio comparativo doble ciego controlado con placebo. La duración del tratamiento fue de nueve semanas y el seguimiento, de un año.

\author{
Lugar \\ Cuatro estados de Estados Unidos
}

\section{Pacientes}

Participaron 893 sujetos mayores de 18 años de ambos sexos que fumaban, al menos, 15 cigarrillos por día y estaban motivados para dejar de fumar. Eran ang loparlantes, no tenían depresión clínica ni otro trastorno psiquiátrico, ni antecedentes de trastornos convulsivos u otra patología clínica severa. No habían utilizado previamente ni estaban utilizando bupropión o algún método para dejar de fumar al momento de ingresar al estudio.

\section{Intervención \\ Se randomizó a los pacientes en cuatro grupos que recibieron: 1) bu- propión $(n=244)$ durante nueve semanas $(150 \mathrm{mg}$ diarios los primeros tres días y, luego, 150mg dos veces por día); 2) parches de nicotina $(\mathrm{n}=244)$ durante ocho semanas ( $21 \mathrm{mg}$ diarios desde la segunda sema- na a la séptima, $14 \mathrm{mg}$ durante las semanas octava y novena y $7 \mathrm{mg}$ en la novena semana); 3 ) ambos tratamientos $(n=245)$; 4) placebo $(n=160)$. Los pacientes de los cuatro grupos recibieron consejos y so- porte telefónico.}

\section{Medición de los resultados}

El resultado principal fue la prevalencia de abstinencia a los seis y 12 meses del seguimiento.

Se definió abstinencia como el no haber fumado desde la consulta previa más una concentración de monóxido de carbono en el aire espirado menor a $10 \mathrm{ppm}$.

Se consideró que un sujeto era un abstinente permanente si no había fumado desde el día que había comenzado el tratamiento, confirmado por la medición de monóxido de carbono en el aire espirado en todas Las consultas de seguimiento durante los 12 meses del estudio. Los resultados secundarios fueron el aumento de peso, los síntomas de abstinencia y la modificación del puntaje de la Escala de Beck para depresión.

\section{Resultados}

El porcentaje de abstinencia a los 12 meses fue de $15.6 \%$ en el grupo placebo, $16.4 \%$ en el grupo que usó parches de nicotina, $30.3 \%$ en el grupo bupropion ( $p<0.001$ ) y $35.5 \%$ en el grupo de tratamiento combinado $(p<0.001)$. No hubo diferencias significativas en el aumento de peso luego de la séptima semana.

Los cuatro grupos tuvieron aumentos significativos en los síntomas de abstinencia durante la primera semana de tratamiento $(p<0.001)$, que se hicieron menores en los tres grupos de tratamiento activo luego de 1 día de dejar el cigarrillo. El tratamiento no modificó los puntajes de la Escala de Depresión de Beck, que se mantuvieron dentro de límites normales.

Los efectos adversos más frecuentes fueron el insomnio y la cefalea. La tasa de abandono del tratamiento fue del 34.8\% (mayor en el grupo placebo).

\section{Conclusiones}

El tratamiento con bupropión de liberación continua, solo o combinado con parches de nicotina, mejora significativamente la tasa de abandono del tabaquismo a largo plazo comparado con el parche o el placebo. La diferencia entre el bupropión solo o asociado con parche no fue significativa.

\section{COMENTARIO}

Los tratamientos de reemplazo de la nicotina mejoran en 1.4 a 2.6 veces la tasa de abandono del cigarrillo pero aún un 70 a $80 \%$ de los pacientes vuelven a fumar. Hurt y col. demostraron que el bupropion es efectivo para ayudar a dejar de fumar con una abstinencia a 12 meses que fue del $23 \%$ comparado con placebo ${ }^{1}$.

Este estudio reporta la prevalencia de abstinencia definida como aquella que se presenta desde la visita previa y sólo menciona tímidamente la abstinencia continua desde el comienzo del tratamiento, siendo ésta última la de verdadera relevancia clínica y cuyos resultados son muy inferiores a los reportados por el estudio (15.6\%, 16.4\%, 30.3\% y $35.5 \%$ vs. $5.6,9.8,18.4$ y $22.5 \%$ para placebo, parche de nicotina, bupropion y bupropion mas parche de nicotina, respectivamente).

El beneficio atribuible al uso de bupropion más parche de nicotina comparado con placebo fue de $16.9 \%$, necesitándose tratar a solo seis

* Ver Glosario pacientes para que uno se beneficie con la intervención, manteniendose al menos un año en abstinencia (NNT)*

Para poder trasladar este estudio a nuestra práctica cotidiana no debemos olvidar el intenso soporte no farmacológico que recibieron los participantes (telefónico y presencial) y el hecho de que fueron sujetos voluntarios. Es importante recordar que el bupropion disminuye el umbral convulsivo y, por lo tanto, deberá ser indicado con precaución en pacientes susceptibles.

El bupropion, solo o asociado a los parches de nicotina, se presenta como una nueva herramienta para ayudar a nuestros pacientes fumadores a combatir la primera causa individual de mortalidad en el mundo, y si bien los resultados no son tan importantes como los reportados por los autores, la tasa de éxito del tratamiento nos obliga a conocerlo y a incorporarlo como una eficaz alternativa.

\section{Dra. Silvina Benchetrit}

Unidad de Medicina Familiar y Preventiva. Hospital Italiano de Buenos Aires. 